\title{
COMUNICAÇÃO INTERNA NAS ORGANIZAÇÕES
}

Uma organização burocrática é caracterizada pela impessoalidade nas relações de trabalho, pela importância do papel do administrador profissional e pelo formalismo, pois sua autoridade deriva de um sistema de normas racionais, escritas e exaustivas. Na empresa, a comunicação interna é utilizada para formalizar e transmitir suas estratégias, procedimentos, valores e conduta, obedecendo a um fluxo de informações determinado pela hierarquia, cargos e funções, além de ser fundamental para a tomada de decisões. No cotidiano das organizações, existe também a comunicação informal, (conhecida como "rádio-peão" ou grapevine, em inglês), meio de comunicação extraoficial impossivel de ser eliminado, por ser intrínseco à necessidade humana. Costuma ser ignorado pelos gestores, mas deveria estar alinhado à comunicação formal. As indicações elaboradas pela professora Roseli Morena Porto (FGV/EAESP), propiciam uma visão aprofundada sobre essa função da comunicação estratégica empresarial.
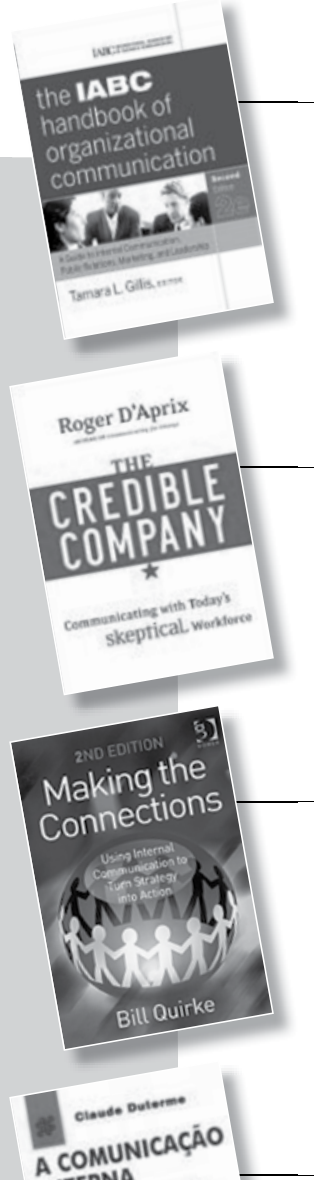
A COMUNA INTERNA

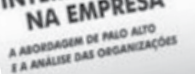

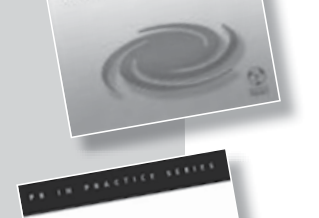

Effective Internal Communication

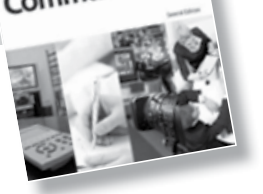

THE IABC HANDBOOK OF ORGANIZATIONAL COMMUNICATION: a guide to internal communication, public relations, marketing and leadership. Tamara Gillis (Ed). San Francisco: Jossey-Bass, 2011. 576 p. Editado desde 2002 pela International Association of Business Communicators, que congrega estudiosos e profissionais da comunicação em 80 países, a obra é uma coletânea de artigos divididos de acordo com as áreas citadas no subtítulo. Em comunicação interna, o foco dos textos é a gestão da comunicação direcionada aos colaboradores da empresa: diversidade, mensuração, integração e envolvimento de funcionários. Os conceitos de comunicação são ilustrados por casos e relacionados a temas como globalização, crosscultural, ROl etc.

THE CREDIBLE COMPANY: communicating with a skeptical workforce. Roger D'Aprix. San Francisco: Jossey-Bass, 2008. 192 p. Com base em sua experiência como executivo e consultor para grandes empresas no setor de tecnologia, o autor oferece uma receita prática para uma comunicação eficaz direcionada a funcionários céticos. A estrutura do livro usa o acrônimo INFORMS, formado pelos princípios: Informação, Necessidade no Trabalho, Comunicação Face a Face, Openness, Research, Mercado e Strategy. Exemplos reais ilustram os acertos e erros das organizações na comunicação com a força de trabalho.

MAKING THE CONNECTIONS: using internal communication to turn strategy into action. Bill Quirke. 2nd ed. Hampshire: Gower Publishing Limited, 2008. 384 p. 0 autor analisa como as empresas podem obter melhores resultados utilizando a comunicação interna para concretizar suas estratégias de diferenciação, melhoria de qualidade, serviço ao cliente, inovação e gestão da mudança de modo mais eficaz e adicionando valor à organização. Ao longo do livro, salienta a importância da comunicação interna informal para transmissão de informações e como os líderes podem utilizá-la. 0 livro traz descrição detalhada de casos empresariais, por exemplo, BMW e Starbucks.

A COMUNICAÇÃO INTERNA NA EMPRESA: a abordagem de Palo Alto e a análise das organizações. Claude Duterme. Lisboa: Instituto Piaget, 2008. 205 p. Escrita pelo psicoterapeuta e pesquisador do Instituto Gregory Bateson, a obra aplica os conceitos da escola de Palo Alto ao mundo empresarial. Segundo ela, a comunicação humana é um sistema de inter-relações entre indivíduos e seus contextos. No ambiente das organizações, a comunicação é um desafio de gestão e de intervenção, apresentando a comunicação interna como uma intervenção no sistema de comunicação. Aborda os temas motivação, relação nos grupos, relações públicas internas e comunicação informal.

EFFECTIVE INTERNAL COMMUNICATION. Lyn Smith e Pamela Mounter. 2nd ed. London: Kogan Page, 2008. 240 p. 0 livro inicia com uma abordagem histórica sobre a evolução da comunicação com funcionários. Segue com questões relacionadas à gestão da comunicação interna para empresas de diferentes tamanhos, tais como: setores, legislação, canais e tecnologia. A segunda parte propõe a aplicação prática da mensuração, terceirização, situações de crise, diversidade e gestão da mudança, tendo como exemplos empresas britânicas. Casos empresariais também ilustram os conceitos sobre semiótica, cultura organizacional e liderança. 